\title{
ENTREPRENEUR
}

Jurnal Bisnis Manajemen Dan Kewirausahaan

Program Studi Manajemen Fakultas Ekonomika dan Bisnis Universitas Majalengka

Published every January and July e-ISSN : 2776-2483, p-ISSN: 2723-1941

Available online http://ejournal.unma.ac.id/index.php/entrepreneur

\section{Analisis Pengaruh Return On Asset (ROA) Dan Return On Equity (ROE) Terhadap Harga Saham PT. INDOSAT Tbk}

\author{
Roslina $^{1}$ dan Alwi ${ }^{2}$ \\ Sekolah Tinggi Ilmu Ekonomi Bima \\ Email: roslina17.stiebima@gmail.com
}

\begin{abstract}
Before investing, investors must know and choose stocks that can provide benefits by assessing the ratio of return on assets (ROA) and return on equity (ROE). This study aims to observe and analyze the effect of return on assets (ROA) and return on equity (ROE) on the stock price of Pt. Indosat Tbk. This research is an associative type, using quantitative data from secondary data sources. The population in this study is the Financial Statements of Pt. Indosat, Tbk. Which is calculated from the beginning of going public for the period 19942020, which is for 25 years. The sample used is the period 2006-2019, which is 14 years at Pt.IndosatTbk which is listed on the Indonesian stock exchange. The sampling technique used in this study is purposive sampling with the sampling criteria in this study are updated financial statement data for 14 years from 2006-2019. 2019. The research instrument used is in the form of financial statement data consisting of a statement of net income, total assets, total equity and profit and loss of the company to get the share price value for the period 2006-2019. Data collection techniques used are documentation and literature study. The data analysis technique used is the classical assumption test, multiple linear regression analysis, multiple correlation coefficients, determination test, $t$ test and $f$ test. The results showed that return on assets (ROA) and return on equity (ROE) had a significant effect on the stock price of PT. Indosat Tbk.
\end{abstract}

Keywords: Return On Asset; Return On Equity; Stock Price 


\section{ENTREPRENEUR}

\section{Jurnal Bisnis Manajemen Dan Kewirausahaan}

Program Studi Manajemen Fakultas Ekonomika dan Bisnis Universitas Majalengka

Published every January and July e-ISSN : 2776-2483, p-ISSN: 2723-1941

Available online http://ejournal.unma.ac.id/index.php/entrepreneur

\section{PENDAHULUAN}

Pasar modal sangat memiliki peran penting dalam kegiatan ekonomi, terutama di negara yang menganut sistem ekonomi pasar, pasar modal menjadi salah satu sumber kemajuan ekonomi karena dapat menjadi sumber dan alternatif bagi suatu perusahaan selain bank. Pasar dapat menjadi alternatif pembiayaan untuk mendapatkan modal dengan biaya yang sangat relatif murah dan juga tempat untuk berinvestasi jangka pendek dan jangka panjang (Ani, et.al, 2019).

Menurut Efendi dan Ngatno (2018) investasi adalah komitmen atas sejumlah dana atau sumber daya lainnya yang dilakukan pada saat ini, dengan tujuan untuk memperoleh sejumlah keuntungan di masa yang akan datang. Salah satu aspek yang dinilai oleh investor adalah kinerja keuangan karena pada prinsipnya semakin baik prestasi perusahaan maka akan meningkatkan permintaan saham perusahaan tersebut, sehingga pada gilirannya akan meningkatkan pula harga saham perusahaan.

Sebelum melakukan investasi para investor juga harus mengetahui dan memilih saham-saham yang dapat memberikan keuntungan bagi perusahaannya. Investor juga membutuhkan informasi laporan keuangan perusahaan untuk membantu proses kegiatan investasinya. Menurut Sunariyah dalam Permatasari, et. al (2019) analisis investasi saham merupakan hal yang mendasar untuk diketahui para pemodal, mengingat tanpa analisis yang baik dan rasional para pemodal akan mengalami kerugian ini menunjukan bahwa harga pasar saham suatu perusahaan dianggap dapat mencerminkan penilaian investor secara keseluruhan atas setiap ekuitas yang dimiliki perusahaan. Menurut Kasmir dalam Sorongan (2019) menyatakan bahwa nilai suatu perusahaan dapat ditunjukkan dengan harga saham. Dengan demikian memaksimumkan nilai pasar perusahaan sama artinya memaksimumkan nilai pasar saham.

Analisis rasio keuangan adalah menggambarkan kondisi keuangan dan hasil usaha suatu perusahaan pada saat tertentu atau jangka waktu tertentu (Sofyan, 2011:105). Terdapat berbagai macam analisis ratio keuangan yang digunakan dalam mengukur kinerja keuangan perusahaan terhadap harga saham salah satunya adalah analisis rasio profitabilitas. Analisis rasio profitabilitas diukur untuk mengukur sejauh mana rasio-rasio tersebut berpengaruh terhadap harga saham. Analisis rasio profitabilitas menunjukkan keberhasilan perusahaan didalam menghasilkan keuntungan (Sutrisno, 2008:215).

Profitabilitas dapat diukur melalui Return On Asset (ROA) dan Return On Equity (ROE). Rasio Return On Asset (ROA) digunakan manajemen untuk mengukur keberhasilan dalam menghasilkan laba. Return On Asset (ROA) yaitu pengembalian atas aktiva merupakan suatu ukuran keseluruhan profitabilitas perusahaan, rasio ini membandingkan imbalan untuk pemegang saham dan kreditor dengan jumlah aset. Rasio Return On Asset (ROA) digunakan mengukur kemampuan tingkat efektivitas penggunaan asset dalam menghasilkan laba bersih dalam suatu perusahaan.

Return On Equity (ROE) menunjukkan tingkat pengembalian yang dihasilkan manajemen perusahaan atas modal yang ditanam oleh pemegang saham, sesudah dipotong kewajiban kreditur menurut (Rusdin, 2006:144). Kaitannya harga saham, rasio ini menjadi bahan analisis investor 


\section{ENTREPRENEUR}

Jurnal Bisnis Manajemen Dan Kewirausahaan

Program Studi Manajemen Fakultas Ekonomika dan Bisnis Universitas Majalengka

Published every January and July e-ISSN : 2776-2483, p-ISSN: 2723-1941

Available online http://ejournal.unma.ac.id/index.php/entrepreneur

yang mendasarkan jumlah investasi yang akan ditanamkannya tentunya harus memperhitungkan perbandingan penghasilan yang didapatnya dibandingkan dengan jumlah investasi yang telah dilakukannya.

Pt. Indosat, Tbk. (Sebelumnya bernama Indosat Ooredoo) adalah salah satu perusahaan penyedia jasa telekomunikasi dan jaringan telekomunikasi di indonesia. Perusahaan ini menawarkan saluran komunikasi untuk pengguna telpon genggam dengan pilihan prabayar maupun pascabayar dengan merek IM3 Ooredoo, jasa lain yang disediakan adalah saluran komuniksi via suara dan telpon tetap (fixed) termasuk sambungan langsung internasional IDD (Internasional Direct Dialing).Indosat Ooredoo juga menyediakan layanan multimedia, internet dan komunikasi data (MIDI= Multimedia,Internet dan data communication services). Pada tahun 2011, Indosat Ooredoo menguasai $21 \%$ pangsa pasar. Pada tahun 2013, Indosat Ooredoo memiliki 58,5 juta pelanggan untuk telpon genggam, pada tahun 2015, indosat ooredoo mengalami kenaikan jumlah pelanggan sebesar 68,5 juta pelanggan dengan presentase naik $24,7 \%$ dibandingkan periode tahun 2014 sebesar 34,9 juta pelanggan.

Grafik 1. Harga Saham Pt. Indosat Tbk Tahun 2006-2019

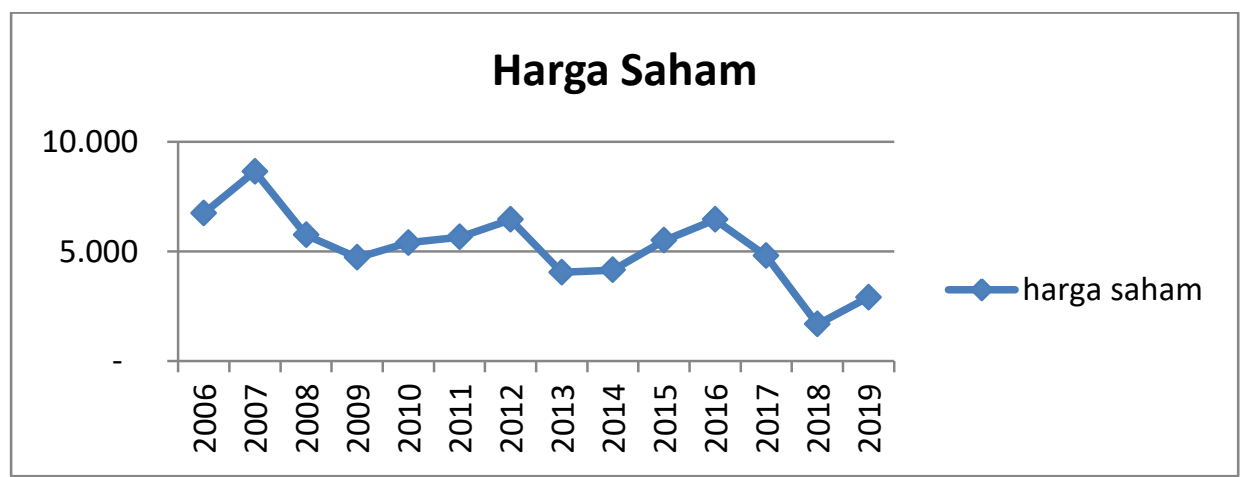

Grafik 1 diatas, mengambarkan perkembangan harga saham perusahaan $\mathrm{Pt}$. Indosat, Tbk tahun 2006-2019, didalam grafik tersebut menunjukan perubahan harga saham yang fluktuatif (naik turun). Harga saham pada tahun 2006 sebesar 6,750 naik pada tahun 2007 sebesar 8,650 dimana pada tahun 2008 dan 2009 harga saham mengalami penurunan dikisaran harga 5,750 dan 4,725 turun sebanyak 1,025 yang sebelumnya naik pada tahun 2007 sebesar 8,650 . Selain terjadi penurunan pada harga saham Pt. Indosat, Tbk juga mengalami kenaikan pada tahun 2006, 2007, 2010, 2011 dan 2012 sebesar $6,750,8,650,5,400,5,650$ dan pada tahun 2012 sebesar 6,450 naik sebanyak 800. hal ini menunjukan kinerja perusahaan yang baik pada kurun waktu 5 tahun terakhir tersabut, khususnya pada tahun 2007 merupakan nilai saham tertinggi selama kurun waktu 2006-2019. Setelah mengalami kenaikan, terjadi lagi penurunan pada tahun 2013 dengan harga saham sebesar 4,050. Pada tahun 2014, 2015 dan 2016 kembali mengalami peningkatan saham sebasar 4,150, tahun 2015 sebesar 5,500 dan pada tahun 2016 sebesar 6,450 naik 950 namun pada tahun 2017-2018 terjadi lagi penurunan dengan harga 4,800, tahun 2018 sebesar 1,685, turun menjadi 


\section{ENTREPRENEUR}

Jurnal Bisnis Manajemen Dan Kewirausahaan

Program Studi Manajemen Fakultas Ekonomika dan Bisnis Universitas Majalengka

Published every January and July e-ISSN : 2776-2483, p-ISSN: 2723-1941

Available online http://ejournal.unma.ac.id/index.php/entrepreneur

sebesar 3,115 kemudian ditutup pada tahun 2019 dengan harga 2,910 naik sebesar 1,225, Harga yang diperoleh pada tahun 2019 sebesar 2,910.

Berdasarkan dari hasil deskripsi grafik diatas, dapat disimpulkan bahwa penjualan pada Pt. Indosat, Tbk mengalami fluktuatif, hal ini disebabkan kuat lemahnya kurs rupiah terhadap mata uang asing, banyak persaingan penjualan, kurangnya daya minat beli konsumen sehingga berdampat pada fluktuatifnya harga saham. Hal ini yang melatarbelakangi penulis tertarik untuk melakukan sebuah penelitian mengenai harga saham dengan judul penelitian "Analisis pengaruh return on asset (ROA) dan return on equity (ROE) terhadap harga saham pada Pt. Indosat, Tbk.

\section{KERANGKA TEORITIS DAN HIPOTESIS}

\section{Pasar Modal}

Menurut Fahmi (2012) "Pasar Modal adalah tempat dimana berbagai pihak khususnya perusahaan menjual saham (stock) dan obligasi (bond) dengan tujuan dari hasil penjualan tersebut nantinya akan dipergunakan sebagai tambahan dana atau memperkuat dana perusahaan". Pasar modal (capital market) merupakan pasar untuk berbagai instrumen keuangan jangka panjang yang bisa diperjualbelikan, baik surat utang (obligasi), ekuiti (saham), reksa dana, instrumen derivatif maupun instrumen lainnya. Pasar modal dapat bermanfaat bagi investor, emiten, pemerintah dan lembaga penunjang lainnya.

\section{Saham}

Menurut Fahmi (2012) saham merupakan sertifikat yang menunjukkan bukti atas kepemilikan perusahaan dimana pemegang saham memiliki hak klaim atas penghasilan dan aktiva perusahaan tersebut.
Kepemilikan seseorang terhadap suatu perusahaan tergantung dari seberapa besar modal yang ditanamkan di perusahaan tersebut.

\section{Harga Saham}

Menurut Aryaningsih, et.al (2018) harga saham merupakan cerminan dari kinerja keuangan suatu perusahaan. Pada periode singkat harga saham bisa berfluktuatif, maka akhir periode penutupan harga saham merupakan acuan yang tepat dalam membandingkan atau menganalisis suatu penelitian. Menurut Tandelilin dalam Vireyto dan Sulasmiyati (2017) harga saham merupakan cerminan dari ekspektasi investor terhadap faktor-faktor earning, aliran kas, dan tingkat return yang diisyaratkan investor, yang mana ketiga faktor tersebut juga sangat dipengaruhi oleh kondisi ekonomi makro.

\section{Return On Asset (ROA)}

$$
\text { Menurut Gitman }
$$

mengungkapkanbahwa return on asset ialah rasio yang mengukur keseluruhan efektivitas manajemen dalam menghasilkan keuntungan dengan asset yang tersedia, semakin tinggi return perusahaan terhadap total asset maka semakin baik.

\section{Return On Equity (ROE)}

Menurut Kasmir dalam Jannah and Rimawan (2020) return on equity adalah untuk alat untuk mengukur laba bersih setelah pajak dengan modal sendiri. Rasio Return On Equity ini menunjukan efisiensi penggunaan modal sendiri. Apabila rasio ini semakin tinggi, maka semakin baik pula kondisi perusaahn tersebut, itu artinya posisi perusahaan akan semakin kuat begitupula sebaliknya. 


\section{ENTREPRENEUR}

Jurnal Bisnis Manajemen Dan Kewirausahaan

Program Studi Manajemen Fakultas Ekonomika dan Bisnis Universitas Majalengka

Published every January and July e-ISSN : 2776-2483, p-ISSN: 2723-1941

Available online http://ejournal.unma.ac.id/index.php/entrepreneur

\section{Pengaruh Return On Asset (ROA)} Terhadap Harga Saham

Menurut Ani, et.al (2019) return on asset adalah rasio yang digunakan untuk mengukur keuntungan bersih yang diperoleh dari penggunaan aktiva. Dengan kata lain, semakin tinggi rasio ini maka semakin baik produktivitas aset dalam memperoleh keuntungan bersih. Hal ini selanjutnya akan meningkatkan daya tarik perusahaan kepada investor dengan meningkatan daya tarik perusahaan menjadikan perusahaan tersebut semakin diminati investor, karena tingkat pengembalian akan semakin besar, ini akan berdampak terhadap harga saham dari perusahaan tersebut di pasar modal juga akan semakin meningkat sehingga return on asset akan berpengaruh terhadap harga saham perusahaan.

H1: Return On Asset (ROA) Berpengaruh Signifikan Terhadap Harga Saham Pada Pt. Indosat Tbk

\section{Pengaruh Return On Equity (ROE) Terhadap Harga Saham}

Menurut Riyadi dalam Umar dan Savitri (2020) return on equity adalah perbandingan antara laba bersih dengan modal inti perusahaan. Rasio ini sangat penting bagi para pemegang saham dan calon investor, karena jika return on equity yang tinggi berarti para pemegang saham akan memperoleh dividen yang tinggi pula dan kenaikan return on equity akan menyebabkan kenaikan harga saham.

H2: Return On Equity (ROE)Berpengaruh Signifikan Terhadap Harga Saham Pada Pt. Indosat Tbk

Pengaruh Return On Asset (ROA) dan Return On Equity (ROE) Terhadap Harga Saham
Menurut Sartono dalam Sunaryo (2011) kemakmuran pemegang saham akan meningkat apabila harga saham yang dimilikinya meningkat. Rasio return on asset dan return on equity dapat menjadi faktor yang dapat menjadi penyebab yang harga saham meningkat dengan stabil. Sementara itu harga saham terbentuk di pasar modal dan ditentukan oleh beberapa faktor seperti laba per lembar saham.

H3: Return On Asset (ROA) dan Return On Equity (ROE)Berpengaruh Signifikan Terhadap Harga Saham Pada Pt. Indosat Tbk

Kabupaten Bima.

\section{METODELOGI PENELITIAN Jenis Penelitian}

Dalam penelitian ini digunakan jenis penelitian asosiatif yaitu suatu penelitian yang bersifat mengetahui hubungan antara dua variabel atau lebih dan mempunyai tingkat yang lebih bila di bandingkan dengan penelitian deskriptif dan komparatif (Sugiyono, 2015).

\section{Jenis Dan Sumber Data}

Jenis data yang digunakan dalam penelitian ini adalah data kuantitatif dari sumber data sekunder, dimana dalam penelitian ini data pada perusahaan Pt.Indosat, Tbk yang sahamnya terdaftar di Bursa Efek Indonesia periode 2006-2019 dengan mengakses website resmi Bursa Efek Indonesia, www.idx.co.id.

\section{Populasi, Sampel Dan Sampling Penelitian}

Populasi adalah wilayah generalisasi yang terdiri atas:obyek/subyek yang mempunyai kuantitas dan karateristik tertentu yang ditetapkan oleh peneliti untuk dipelajari dan kemudian ditarik kesimpulannya (Sugiyono, 2015). Populasi 


\section{ENTREPRENEUR}

\section{Jurnal Bisnis Manajemen Dan Kewirausahaan}

Program Studi Manajemen Fakultas Ekonomika dan Bisnis Universitas Majalengka

Published every January and July e-ISSN : 2776-2483, p-ISSN: 2723-1941

Available online http://ejournal.unma.ac.id/index.php/entrepreneur

dalam penelitian ini adalah Laporan Keuangan Pt. Indosat, Tbk Yang dihitung dari awal Go Publik Priode tahun 1994-2020 yaitu 25 tahun.

Sugiyono (2015) mengungkapkan bahwa sampel adalah bagian dari jumlah dan karakteristik yang dimiliki oleh populasi tersebut. Sampel yang digunakan adalah priode tahun 2006-2019 yaitu 14 tahun pada Pt.Indosat, Tbk yang terdaftar dibursak efek Indonesia.

Teknik sampling yang digunakan dalam penelitian ini adalah purposive sampling. Menurut Sugiyono (2015) purposive sampling adalah teknik untuk menentukan sampel penelitian dengan beberapa pertimbangan tertentu yang bertujuan agar data yang diperoleh nantinya bisa lebih berpresentatif, kriteria sampling dalam penelitian ini adalah data laporan keuangan terupdate selama 14 tahun dari tahun 20062019.

\section{Instrumen Penelitian Dan Teknik Pengumpulan Data}

\section{HASIL DAN PEMBAHASAN}

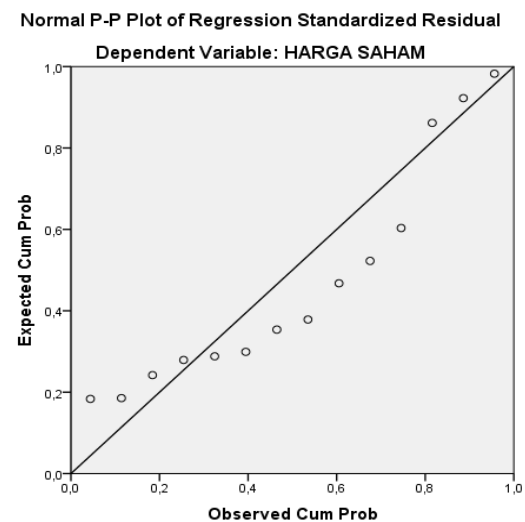

Gambar 2. Uji Normalitas

Sumber Data: Data primer diolah Spss v20 2021

Gambar 2 di atas, menunjukkan bahwa grafik Normal P-P of Regression Standardized Residual menggambarkan
Instrumen penelitian yang digunakan adalah berupa data laporan keuangan yang terdiri dari laporan laba bersih, total asset, jumlah ekuitas dan laba rugi perusahaan untuk mendapatkan nilai harga saham periode tahun 2006-2019. Tekhnik pengumpulan data yaitu yang digunakan dalam penelitian ini yaitu:

Dokumentasi, yaitu suatu cara yang digunakan untuk memperoleh data dan informasi dalam bentuk buku,arsip,dokumen tulisan angka,dan gambambaran yang berupa laporan serta keterangan yang dapat mendukung penelitian.

Studi Pustaka, yaitu metode penegumpulan data yang dilakukan dengan mengumpulkan sejumlah buku-buku, majalah, yang berkenaan dengan masalah dan tujuan penelitian.

\section{Teknik Analisa Data}

Teknik analisa data yang digunakan dalam penelitian ini adalah uji asumsi klasik, analisis regresi linear berganda, koefisisen korelasi berganda, uji determinasi, uji t dan uji $\mathrm{f}$.

Tabel 1. Hasil Uji kolmogorov-smirnov One-Sample Kolmogorov-Smirnov Test

\begin{tabular}{|c|c|c|}
\hline \multicolumn{3}{|c|}{ One-Sample Kolmogorov-Smirnov Test } \\
\hline \multicolumn{3}{|c|}{$\begin{array}{l}\text { Unstandardized } \\
\text { Residual }\end{array}$} \\
\hline $\mathrm{N}$ & & 14 \\
\hline \multirow[t]{2}{*}{ Normal Parameters } & Mean & $0 \mathrm{E}-7$ \\
\hline & $\begin{array}{l}\text { Std. } \\
\text { Deviation }\end{array}$ & 1,29036526 \\
\hline \multirow{3}{*}{$\begin{array}{l}\text { Most Extreme } \\
\text { Differences }\end{array}$} & Absolute & ,158 \\
\hline & Positive &, 076 \\
\hline & Negative &,- 158 \\
\hline \multicolumn{2}{|l|}{ Kolmogorov-Smirnov Z } &, 593 \\
\hline \multicolumn{2}{|l|}{ Asymp. Sig. (2-tailed) } & 874 \\
\hline \multicolumn{3}{|c|}{ a. Test distribution is Normal. } \\
\hline \multicolumn{3}{|c|}{ b. Calculated from data. } \\
\hline \multicolumn{3}{|c|}{ Sumber : Data primer diolah Spss. v20 2021} \\
\hline
\end{tabular}




\section{ENTREPRENEUR}

\section{Jurnal Bisnis Manajemen Dan Kewirausahaan}

Program Studi Manajemen Fakultas Ekonomika dan Bisnis Universitas Majalengka

Published every January and July e-ISSN : 2776-2483, p-ISSN: 2723-1941

Available online http://ejournal.unma.ac.id/index.php/entrepreneur

yang digunakan dalam penelitian ini memenuhi asumsi normalitas.

Untuk memperkuat pengujian normalitas, maka peneliti menambahkan uji kolmogorov-smirnov dengan hasilnya adalah sebagai berikut :

Berdasarkan hasil uji kolmogorofsmirnov di atas, terlihat nilai Asymp.Sig memiliki nilai > 0.05 yaitu sebesar 0,874 .

Tabel 2. Hasil Uji Multikolinearitas

\begin{tabular}{llrl}
\hline \multicolumn{4}{c}{ Coefficients $^{\text {a }}$} \\
\hline Model & \multicolumn{2}{c}{ Collinearity } \\
& & Statistics \\
\cline { 3 - 4 } & & Tolerance & VIF \\
\hline 1 & RETURN ON &, 284 & 3,527 \\
& ASSET (ROA) & & \\
\cline { 2 - 4 } & RETURN ON &, 284 & 3,527 \\
\multicolumn{2}{l}{ EQUITY (ROE) } & & \\
\hline \multicolumn{2}{l}{ a. Dependent Variable: HARGA SAHAM }
\end{tabular}

Sumber : Data primer diolah Spss v20 2021

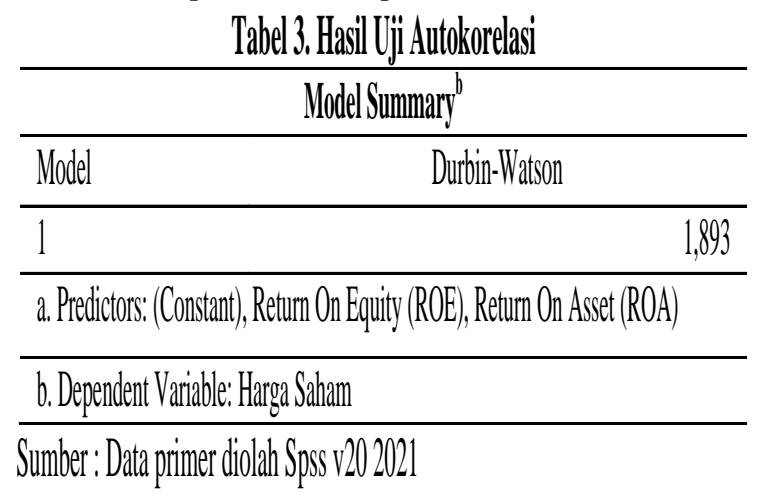

Berdasarkan nilai collinearity statistic dari output di atas, di peroleh nilai tolerance variable return on asset (ROA) dan return on equity (ROE) adalah > 0,10 sementara, nilai VIF untuk variabel return on asset (ROA) dan return on equity (ROE) $<10.00$. Maka dapat di di simpulkan bahwa tidak terjadi gejala multikolineritas.

Berdasarkan grafik scatterplot diatas terlihat mengambarkan pola jelas bahwa
Nilai tersebut menunjukkan data yang digunakan dalam penelitian berdistribusi secara normal sehingga model regresi tersebut layak digunakan untuk memprediksi variabel dependen yaitu harga saham berdasarkan masukan variabel independen yaitu return on asset (ROA) dan return on equity (ROE), ini menyatakan bahwa data penelitian ini layak.

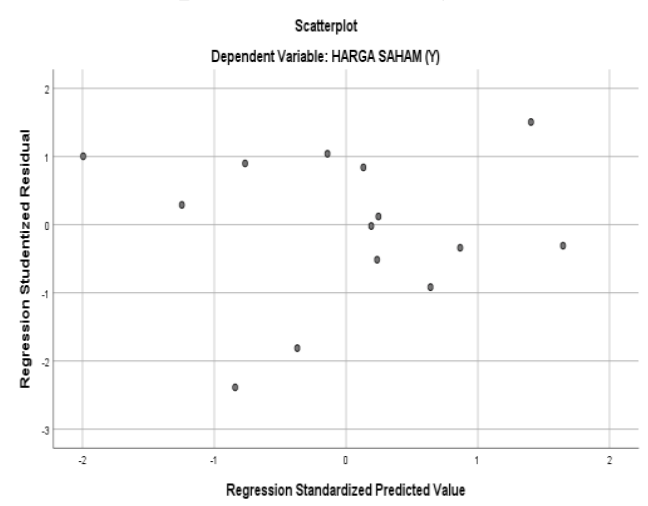

Gambar 3. Hasil Uji Heteroskedastisitas

Tabel 4. Hasil Uji Regresi Linear Berganda

\begin{tabular}{|c|c|c|c|c|}
\hline \multicolumn{5}{|c|}{ Coefficients $^{a}$} \\
\hline \multirow[t]{3}{*}{ Mode } & & \multirow{2}{*}{\multicolumn{2}{|c|}{$\begin{array}{c}\text { Unstandardized } \\
\text { Coefficients }\end{array}$}} & Standardized \\
\hline & & & & \\
\hline & & $\mathrm{B}$ & Std. Error & Beta \\
\hline \multirow[t]{3}{*}{1} & (Constant) & 6,189 & 817 & \\
\hline & Return 0n Asset (ROA) & 1,818 &, 473 & 1,230 \\
\hline & Return On Equity (ROE) &,- 645 & 134 & $-1,543$ \\
\hline \multicolumn{5}{|c|}{ a. Dependent Variable: HARGA SAHAM } \\
\hline
\end{tabular}

titik-titik plot berada di atas dan di bawah angka 0 pada sumbu Y. maka dapat disimpulkan bahwa tidak terjadi gejala heteroskedastisitas pada model regresi.

Hasil uji autokolerasi diatas menunjukkan nilai statistik durbin watson sebesar 1,893 dengan nilai DU sebesar 1,6283, maka DU<DW<4-DU sehingga 1, $6283<1,893<2,3717$, maka disimpulkan tidak terjadi autokolerasi. 


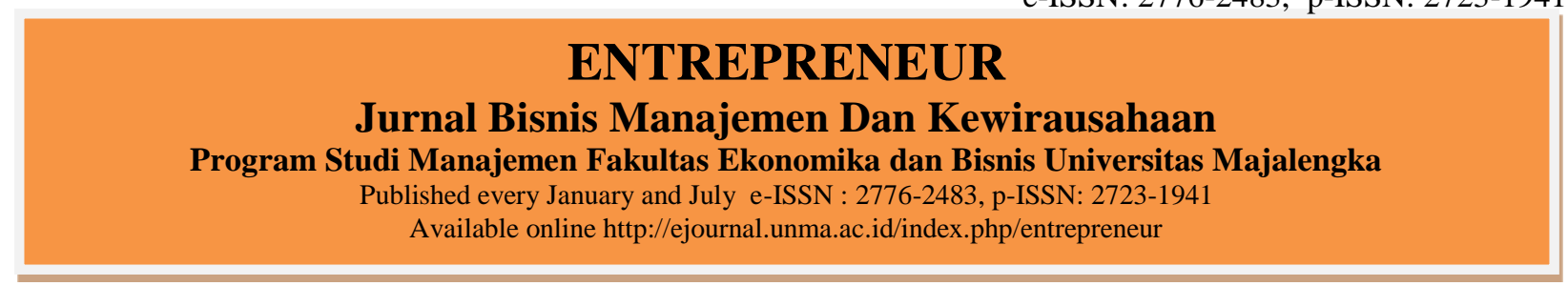

\begin{tabular}{llllr}
\multicolumn{5}{c}{ Tabel 4. Hasil Uji Regresi Linear Berganda } \\
\hline \multirow{4}{*}{ Model } & \multicolumn{4}{c}{ Coefficients $^{\boldsymbol{a}}$} \\
& & \multicolumn{2}{c}{$\begin{array}{c}\text { Unstandardized } \\
\text { Coefficients }\end{array}$} & $\begin{array}{c}\text { Standardized } \\
\text { Coefficients }\end{array}$ \\
\cline { 3 - 5 } & & B & Std. Error & Beta \\
\hline \multirow{2}{*}{1} & (Constant) & 6,189 &, 817 & \\
\cline { 2 - 5 } & Return On Asset (ROA) & 1,818 &, 473 & 1,230 \\
\cline { 2 - 5 } & Return On Equity (ROE) &,- 645 &, 134 & $-1,543$ \\
\hline \multicolumn{2}{l}{ a. Dependent Variable: HARGA SAHAM } & & \\
\hline
\end{tabular}

Sumber :Data Primer Diolah SPSS v20, 2021

Dari hasil analisis regresi dapat diketahui persamaan regresi berganda sebagai berikut:

$\mathrm{Y}=6,189+1,818 \mathrm{X} 1-0,645 \mathrm{X} 2+\mathrm{e}$

Berdasarkan persamaan tersebut, maka dapat dijelaskan sebagai berikut:

1. Nilai konstanta sebesar 6,189 dapat diartikan apabila variabel return on asset (ROA) dan return on equity (ROE) dianggap nol, maka harga saham akan sebesar 6,189.

2. Nilai koefisien beta pada variabel return on asset (ROA) sebesar 1,818 artinya setiap perubahan variabel return on asset (ROA) (X1) sebesar satu satuan, maka akan mengakibatkan perubahan harga saham (Y) sebesar 1,818 satuan, dengan asumsi-asumsi yang lain adalah tetap. Peningkatan satu satuan pada variabel return on asset (ROA) akan meningkatkan harga saham sebesar 1,818 satuan.

3. Nilai koefisien beta pada variabel return on equity (ROE) sebesar - 0,645 artinya setiap perubahan variabel return on equity (ROE) (X2) sebesar satu satuan, maka akan mengakibatkan perubahan harga saham (Y) sebesar -0,645 satuan, dengan asumsi-asumsi yang lain adalah tetap. Penurunan satu satuan pada variabel return on equity (ROE) akan menurunkan harga saham (Y) sebesar 0,645 satuan.

Tabel 5. Hasil Uji Koefisien Kolerasi dan Uji Determinasi

\begin{tabular}{llccr}
\hline \multicolumn{4}{c}{ Model Summary } \\
\hline Model & $\mathrm{R}$ & R Square & $\begin{array}{c}\text { Adjusted R } \\
\text { Square }\end{array}$ & Std. Error of the Estimate \\
\hline 1 &, $825^{\mathrm{a}}$ &, 680 &, 622 & 1,057199 \\
\hline \multicolumn{4}{l}{ a. Predictors: (Constant), Return On Equity (ROE), Return On Asset (ROA) }
\end{tabular}

Sumber :Data Primer Diolah SPSS v20, 2021

Dari hasil tersebut dapat diperoleh nilai $\mathrm{R}$ adalah sebesar 0,825. Hasil tersebut menjelaskan bahwa terdapat pengaruh antara return on asset (ROA) dan return on equity (ROE) terhadap harga saham. Untuk dapat memberi interpretasi terhadap kuatnya pengaruh itu maka dapat digunakan pedoman seperti pada tabel berikut : 


\section{ENTREPRENEUR}

Jurnal Bisnis Manajemen Dan Kewirausahaan

Program Studi Manajemen Fakultas Ekonomika dan Bisnis Universitas Majalengka

Published every January and July e-ISSN : 2776-2483, p-ISSN: 2723-1941

Available online http://ejournal.unma.ac.id/index.php/entrepreneur

Tabel 6. Pembanding Tingkat Hubungan Koefisien Korelasi

\begin{tabular}{cc}
\hline Interval Koofisien & Tingkat Hubungan \\
\hline $0,00-0,199$ & Sangat Rendah \\
$0,20-0,399$ & Rendah \\
$0,40-0,599$ & Sedang \\
$0,60-0,799$ & Kuat \\
$0,80-1,000$ & Sangat Kuat
\end{tabular}

Sumber:Sugiyono,2015

Jadi kolerasi hubungan return on asset (ROA) dan return on equity (ROE) terhadap harga saham sebesar 0,825 berada pada interval $0,80-1,000$ dengan tingkat hubungan sangat kuat.

Pada tabel 5 diatas juga diketahui bahwa nilai $\mathrm{R}$ Square sebesar 0,680 , Jadi

terdapat pengaruh antara return on asset (ROA) dan return on equity (ROE) terhadap harga saham yang besarnya pengaruh tersebut sebesar 0,680 atau $68 \%$, sedangkan sisanya $32 \%$ dipengaruhi oleh faktor lain yang tidak diteliti dalam penelitian ini.

Tabel 7. Hasil Uji t

\begin{tabular}{|c|c|c|c|}
\hline \multicolumn{4}{|c|}{ Coefficients $^{\mathrm{a}}$} \\
\hline & & $\mathrm{t}$ & Sig. \\
\hline \multirow[t]{3}{*}{1} & (Constant) & 7,574 & 000 \\
\hline & $\begin{array}{l}\text { Return On Asset } \\
\text { (ROA) }\end{array}$ & 3,841 & ,003 \\
\hline & $\begin{array}{l}\text { Return On Equity } \\
\text { (ROE) }\end{array}$ & 4,819 & ,001 \\
\hline \multicolumn{4}{|c|}{ a. Dependent Variable: Harga Saham } \\
\hline
\end{tabular}

H1: Return On Asset (ROA) Berpengaruh Signifikan Terhadap Harga Saham Pada Pt. Indosat Tbk

Hasil statistik uji t untuk variable Return On Asset (ROA) diperoleh nilai thitung sebesar 3,841 lebih besar dari pada nilai t tabel sebesar 2,009 (3,841 > 2,009) dengan nilai signifikansi sebesar 0,003 lebih kecil dari $0,05(0,003<0,05)$, maka hipotesis pertama yang menyatakan bahwa "Return On Asset (ROA) Berpengaruh Signifikan Terhadap Harga Saham Pada Pt. Indosat Tbk" Diterima.

Penelitian ini sama seperti penelitian yang dilakukan oleh Permatasari, et.al
(2019) yang menyatakan bahwa Return On Asset (ROA) berpengaruh signifikan terhadap Harga Saham perusahaan sektor jasa di Bursa Efek Indonesia

H2: Return On Equity (ROE)Berpengaruh Signifikan Terhadap Harga Saham Pada Pt. Indosat Tbk

Hasil statistik uji $\mathrm{t}$ untuk harga diperoleh nilai thitung sebesar 4,819 lebih besar dari pada nilai ttabel sebesar 2,009 $(4,819>2,009)$ dengan nilai signifikansi sebesar 0,001 lebih kecil dari 0,05 $(0,001<$ $0,05)$ maka hipotesis kedua yang menyatakan bahwa "Return On Equity 


\section{ENTREPRENEUR}

Jurnal Bisnis Manajemen Dan Kewirausahaan

Program Studi Manajemen Fakultas Ekonomika dan Bisnis Universitas Majalengka

Published every January and July e-ISSN : 2776-2483, p-ISSN: 2723-1941

Available online http://ejournal.unma.ac.id/index.php/entrepreneur

(ROE)Berpengaruh Signifikan Terhadap

Harga Saham Pada Pt. Indosat Tbk" Diterima.

Penelitian ini sama seperti penelitian yang dilakukan oleh Sorongan (2019) yang menyatakan bahwa Return On Equity (ROE) berpengaruh signifikan terhadap Harga Saham pada perusahaan otomotif yang terdaftar di BEI.

Tabel. 8 Hasil Uji F

\begin{tabular}{|c|c|c|c|c|c|c|}
\hline \multicolumn{7}{|c|}{ ANOVA $^{a}$} \\
\hline \multicolumn{2}{|l|}{ Model } & $\begin{array}{l}\text { Sum of } \\
\text { Squares }\end{array}$ & Df & $\begin{array}{l}\text { Mean } \\
\text { Square }\end{array}$ & $\mathrm{F}$ & Sig. \\
\hline \multirow[t]{3}{*}{1} & $\begin{array}{l}\text { Regressi } \\
\text { on }\end{array}$ & 26,178 & 2 & 13,089 & 11,711 &, $002^{\mathrm{b}}$ \\
\hline & Residual & 12,294 & 11 & 1,118 & & \\
\hline & Total & 38,472 & 13 & & & \\
\hline \multicolumn{7}{|c|}{ a. Dependent Variable: Harga Saham } \\
\hline \multicolumn{7}{|c|}{ b. Predictors: (Constant), Return On Equity (ROE), Return On Asset (ROA) } \\
\hline
\end{tabular}

H3: Return On Asset (ROA) dan Return On Equity (ROE)Berpengaruh Signifikan Terhadap Harga Saham Pada Pt. Indosat Tbk

Dari hasil pengujian diperoleh nilai Fhitung sebesar 11,711 dengan nilai Ftabel sebesar 3,89 (11,711>3,89) dengan signifikansi sebesar 0,002 , oleh karena nilai signifikansi lebih kecil dari $0,05(0,002<$ 0,05), maka dapat disimpulkan bahwa hipotesis ketiga yang menyatakan bahwa "Return On Asset (ROA) dan Return On Equity (ROE)Berpengaruh Signifikan Terhadap Harga Saham Pada Pt. Indosat Tbk" Diterima.

Penelitian ini sama seperti penelitian yang dilakukan oleh Simanjuntak dan Janrosl (2021) yang menyatakan bahwa Return On Asset (ROA) dan Return On Equity (ROE) berpengaruh signifikan terhadap Harga Saham di Bursa Efek Indonesia.

\section{KESIMPULAN DAN IMPLIKASI}

Berdasarkan hasil analisa data yang telah dilakukan, uji t statistik menyatakan Return On Asset (ROA) berpengaruh signifikan terhadap Harga Saham pada Pt. Indosat Tbk dan Return On Equity (ROE) berpengaruh signifikan terhadap Harga Saham pada Pt. Indosat Tbk. Berdasarkan uji f statistik menyatakan bahwa Return On Asset (ROA) dan Return On Equity (ROE) berpengaruh signifikan terhadap Harga Saham pada Pt. Indosat Tbk. Hal ini menunjukan bahwa Harga Saham Pt. Indosat Tbk dapat diprediksi dengan rasio Return On Asset (ROA) dan rasio Return On Equity (ROE).

Penulis menyarankan agar Pt. Indosat Tbk sebaiknya terus meningkatkan rasio Return On Asset (ROA) dan rasio Return On Equity (ROE) agar nilai perusahaanya meningkat dan berdampak pada harga saham yang tinggi seperti yang diharapkan oleh perusahaan tersebut. 


\section{ENTREPRENEUR}

Jurnal Bisnis Manajemen Dan Kewirausahaan

Program Studi Manajemen Fakultas Ekonomika dan Bisnis Universitas Majalengka

Published every January and July e-ISSN : 2776-2483, p-ISSN: 2723-1941

Available online http://ejournal.unma.ac.id/index.php/entrepreneur

\section{DAFTAR PUSTAKA}

Ani, N. K. S, Trianasari, Cipta, W. (2019). "Pengaruh ROA Dan ROE Serta EPS Terhadap Harga Saham Sektor Farmasi Yang Terdaftar Di BEI." Jurnal Manajemen 5(2): 148-57.

Aryaningsih, Y. N, Fathoni, A, Harini, C. (2018). "Pengaruh Return on Asset (ROA), Return on Equity (ROE) Dan Earning per Share (EPS) Terhadap Return Saham Pada Perusahaan Consumer Good (Food and Beverages) Yang Terdaftar Di Bursa Efek Indonesia (BEI) Periode 2013-2016." Journal of Management 4(4).

Efendi, F. M, Ngatno. (2018). "Pengaruh Return On Assets (ROA Terhadap Harga Saham Dengan Earning PerShare (EPS) Sebagai Intervening (Studi Kasus Pada Perusahaan Sub SektorTekstil Dan Garmen Yang Terdaftar Di Bursa Efek Indonesia Periode 2013-2016)." Jurnal Administrasi Bisnis 7(1): 1.

Fahmi, I. (2012). "Analisis Kinerja Keuangan."

Gitman, L. J. (2012). Principles of Managerial Finance.

Jannah, W, Rimawan, M. (2020). "Analisis Pengaruh Non Performing Loan (Npl) Terhadap Return on Equity Pada Koperasi Wanita (Kopwan) Kartika Sari Kota Bima." Jurnal Ekonomi Balance 16(1): 107-14.

Permatasari, N. D, Nurlaela, S, Titisari, H. K. (2019). "Return on Assets, Return on Equity, Earning Per Share Terhadap Harga Saham Perusahaan Sektor Jasa
Di Bursa Efek Indonesia." Jurnal Ilmiah Edunomika 3(01): 90-96.

Simanjuntak, S, Janrosl, E. S.V. (2021). "Pengaruh Return on Asset Dan Return on Equity Terhadap Harga Saham Di Bursa Efek Indonesia." SCIENTIA JOURNAL : Jurnal Ilmiah Mahasiswa.

Sorongan, F. A. (2019). "Pengaruh Return on Assets, Return on Equity, Earning Per Share Terhadap Harga Saham Pada Perusahaan Otomotif Yang Terdaftar Bei." JMBI UNSRAT (Jurnal Ilmiah Manajemen Bisnis dan Inovasi Universitas Sam Ratulangi). 6(2): 10614.

Sugiyono. (2015). Metode Penelitian Kuantitatif Kualitatif. Bandung: Alfabeta.

Sunaryo. (2011). "Analisis Pengaruh ROA (Return On Assets), ROE (Return On Equity), Dan EPS (Earning Per Share) Terhadap Harga Saham Pada Kelompok Industri Barang Konsumsi Yang Terdaftar Di BEI (Bursa Efek Indonesia)." Binus Business Review 2(1): 173.

Umar, A. U. A. A, Savitri, N. S. A. (2020). "Analisis Pengaruh Roa, Roe, Eps Terhadap Harga Saham." Jurnal Analisa Akuntansi dan Perpajakan 4(2): 92-98.

Vireyto, N, Sulasmiyati, S. (2017). "Analisis Pengaruh Return On Asset, Return On Equity, Dan Earning Per Share Terhadap Harga Saham (Studi Pada Perusahaan Bank BUMN Yang Listed Di Bursa Efek Indonesia Periode 20062016)." Jurnal Administrasi Bisnis S1 Universitas Brawijaya 51(1): 75-82. 